\title{
Circumcaval Ureter - MDCT \& Retrograde Pyelography Features
}

\author{
Krishna Kumar* \\ DM Wayanad Institute of Medical Sciences, India
}

Submission: December 24, 2016; Published: January 10, 2017

*Corresponding author: Krishna Kumar, Associate Professor of Radio-diagnosis, DM Wayanad Institute of Medical Sciences, Naseera Nagar, Meppadi, Wayanad, Kerala, India, Tel: +91 9447345528; Fax: +91 4936-287287; Email: drmkrishnakumar@gmail.com

\begin{abstract}
The circumcaval ureter is a rare congenital anomaly usually associated with upper urinary tract hydronephrosis. Although it is a congenital anomaly, patients usually do not present with symptoms until the $3^{\text {rd }}$ and $4^{\text {th }}$ decades of life. The Patients main symptoms include right loin pain, recurrent urinary tract infections (UTI) and hematuria. Its rarity and non-specific presentation pose a challenge to surgeons and radiologists in making the correct diagnosis. Differentiation from other causes of urinary tract obstruction, especially the more common urolithiasis, is important for successful surgical management. Current practice has seen Multidetector Computed Tomography (MDCT) rapidly replaces Intravenous Urography (IVU) in the assessment of patients with hydronephrosis. We report a case of Type 1 Circumcaval ureter in a 36 years old female presenting with recurrent urinary tract infection (UTI) \& right loin pain, referred for MDCT \& Retrograde Pyelography (RGP).
\end{abstract}

Keywords: Circumcaval ureter; Hydronephrosis; MDCT; Pre-ureteral vena cava; Retrocaval ureter; RGP

\section{Introduction}

Circumcaval ureter also referred to as Retrocaval ureter or Pre-ureteral vena cava is a rare congenital anomaly with the ureter deviates medially and passes behind the inferior vena cava (IVC), winding around and crossing in front of it from medial to lateral side. It is a vascular compression syndrome which was first reported in 1893 by Hochstetter [1]. The incidence was reported to be approximately 1 in 1000, with male predominance [2]. Retrocaval ureter results from an anomaly in the development of the inferior vena cava [3].

Congenital anomalies that result in the obstruction of the ureter are extremely rare; however, retrocaval ureter is the most common anomaly with a venous cause. Although the anomaly is congenital, patients become symptomatic in their 3rd or 4th decade of life. The anomaly is usually observed in the right side and it may be left sided in case of situs inversus or duplication of IVC. In symptomatic cases, surgical intervention is often required [4]. We report this Retrocaval ureteric anomaly \& Imaging findings in a 36 yrs old female with recurrent UTI \& right loin pain.

\section{Case Report}

A 36 years old female with recurrent UTI \& right loin pain since 6 months, was referred to Radiology \& Imaging department to investigate cause of recurrent UTI. Patient complained of increase in severity of symptoms after consuming lots of liquid or juice. There was no haematuria. The blood pressure at presentation was within normal limits. Total blood count, urinalysis and blood urea and creatinine were normal.

Though clinical examination revealed no abnormality, Ultrasound scan (US) of the abdomen done, showed mild hydronephrosis of the right kidney and dilated upper one third of ureter without any evidence of calculus. Plain radiograph KUB did not show any radio-opaque shadow. Patient underwent MDCT (64 Slice vCT, GE) of abdomen \& pelvis with \& without intravenous contrast. Axial, reformatted coronal \& CT urogram pictures were later reviewed. Plain CT of abdomen showed no evidence of urolithiasis with right mild hydronephrosis \& proximal third hydroureter. Contrast enhanced CT of abdomen \& CT urogram showed Right mild hydronephrosis \& proximal third hydroureter with $\mathrm{S}$ shaped deviation of middle ureter medially at the level of L3 vertebra (Figure 1\&2). The distal two third of right ureter was normal in caliber. The left collecting system, ureter \& Urinary bladder was unremarkable. Initially the cause of right ureteric obstruction was thought to be, due to radiolucent stone or proximal ureteric stricture. 


\section{Current Trends in Clinical \& Medical Imaging}

Retrograde uretero-pyelography (RGP) was done to rule out any cause of ureteric obstruction, which revealed medial displacement of proximal ureter, medial to the L3 pedicle with focal mild narrowing at the junction of proximal third \& lower two third with no intraluminal calculus (Figure3). Retrospective analysis of axial, reformatted coronal CT images \& CT urogram (Figure1\&2) revealed focal retrocaval narrowed segment of right ureter at the junction of lower two third \& proximal third confirming Type 1 Circumcaval ureter. The location of the IVC lateral to right pedicle of the L3 vertebra was clearly demonstrated in our patient.

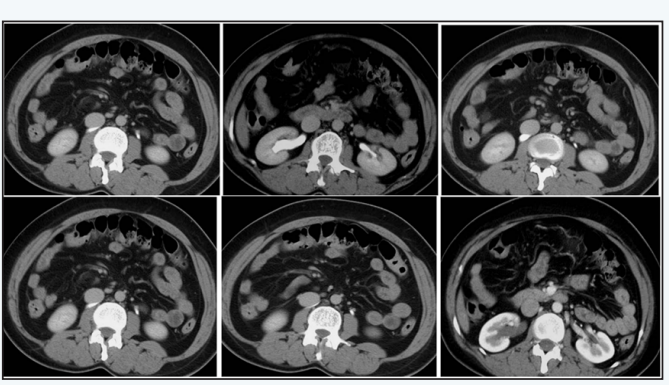

Figure 1(A-F): The axial MDCT shows Right mild hydronephrosis with the inferior ureter coursing posterior \& medial to the IVC.
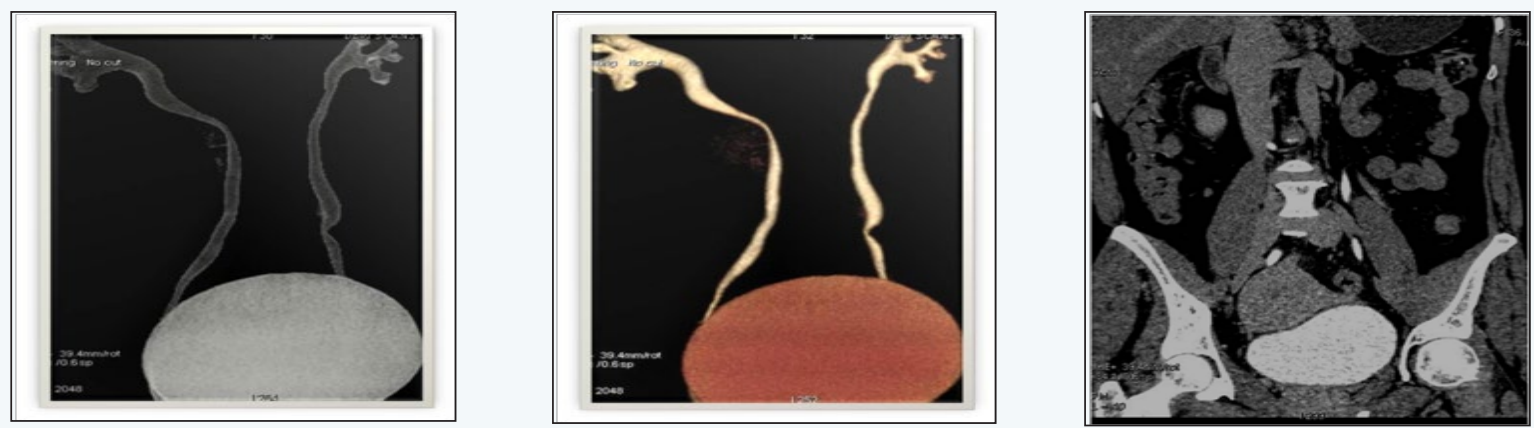

Figure 2(G-I): MDCT Coronal reformatted image (G) demonstrates medial displacement of the right ureter at the level of L3. MIP Coronal reformatted Urogram image $(\mathrm{H}, \mathrm{I})$ demonstrates medial displacement of the middle right ureter with narrowed segment at the junction of proximal third \& lower two third.

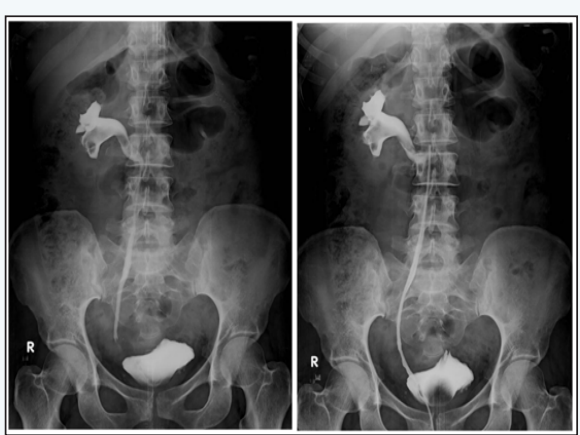

Figure 3(J,K): Right RGP showing an "S" shaped proximal right ureter. The ureter is medial to the pedicle of the L3 vertebral body consistent with Type 1circumcaval ureter.

At surgery, the ureter was dilated up to the lateral edge of the IVC. The retrocaval part of the ureter was found to be stenotic and showed failure of peristaltic transmission. The stenotic ureter was resected, the ureter relocated and end-toend anastomosis was done after confirmation of distal ureteric patency. The post operative IVU was normal and the patient remained asymptomatic.

\section{Discussion}

Retrocaval ureter is a rare congenital anomaly occurring with incidence of about 1 in 1500 people with a three to four times male predominance in autopsy studies [5]. Normally, IVC originates from the supracardinal and subcardinal veins inferior and superior to the kidney, respectively. If the IVC inferior to the kidney is formed by subcardinal vein, it will be located anterior to the ureter and will form a retrocaval ureter. There are two types of retrocaval ureter.

Type 1(low loop) which is more prevalent and has an S-shape or fishhook appearance, and has moderate to severe hydronephrosis in about $50 \%$ of cases with extreme medial deviation of middle ureteric segment. The renal pelvis and upper ureter typically appear elongated and dilated in a "J" or fishhook shape before passing behind the vena cava. The ureter typically deviates medially behind the inferior vena cava, winding about and crossing in front of it from a medial to a lateral direction, to resume a normal course, distally, to the bladder.

Type 2 (high loop) which is sickle shaped and has less medial deviation of the ureter with mild or no associated hydronephrosis and forms about $10 \%$ of cases [6]. In Type 2, the retrocaval segment is at the same level as the renal pelvis.

Medial deviation of the ureter in the lumbar region may be caused by retroperitoneal fibrosis, a retroperitoneal mass, previous surgery as well as by circumcaval ureter [3]. Retrocaval ureter may be asymptomatic or cause symptoms such as flank pain, urinary tract infection, hematuria, or calculus formation $[7,8]$. The hydronephrosis may be due to kinking of the ureter, a ureteric segment that is a dynamic or compression against the psoas muscle [9]. Circumcaval ureter is usually observed on right side, but bilateral circumcaval ureters have also been reported [10]. The various anomalies associated with retrocaval ureter are Horseshoe kidney, double IVC and left retrocaval ureter with Goldenhar syndrome [11,12]. 


\section{Current Trends in Clinical \& Medical Imaging}

Abdominal ultrasound (US) demonstrates hydronephrosis \& proximal third hydroureter. The findings on IVU while suggestive of circumcaval ureter are not diagnostic. IVU usually does not demonstrate the middle and distal ureter requiring a RGP to demonstrate the ureter and hence confirm the diagnosis. A RGP done in conjunction with an inferior vena cavogram has been advocated in the past for making the diagnosis. MDCT is preferred over IVU by physicians because of its high sensitivity (96\%), specificity (99\%), and accuracy (96\%) for the detection of ureteric calculus [13]. MDCT scan may define the ureter and inferior vena cava anomalies obviating the need for a RGP and is considered an investigation of choice [14].

Magnetic Resonance Imaging (MRI) can nicely demonstrate the course of a Pre-ureteral vena cava and may be a more detailed and less invasive imaging modality, without exposure to radiation, when compared with CT and RGP [2]. However, it may not be practical in our setting due to its high cost and limited availability in some health centers. In our case, the main focus was to detect possible ureteric calculus that was thought to cause the obstruction; therefore, when US and CT did not show any calculus, invasive procedures, such as cystoscopy and RGP was performed. In the present case, the MDCT delineation of the ureter and its course in relation to the IVC and location of IVC lateral to the right pedicle of the L3 vertebra were diagnostic of Type 1 Circumcaval ureter (Figure 1\&2). Whereas only 6\% of normal individuals have an IVC lateral to the right pedicle of L3 vertebra, all the reported cases of Circumcaval ureter in the literature have an IVC lateral to the pedicle.

Conservative treatment and periodical examination should be given to those patients without hydronephrosis, infection, and stone formation. Surgical management is reserved for the type 1 cases that are usually symptomatic. Transperitoneal and retroperitoneal laparoscopic repair of the retrocaval ureter has been described offering advantages of a shorter hospital stay and early recovery $[15,16]$.

\section{Conclusion}

Circumcaval ureter is a rare congenital anomaly with the ureter passing posterior to IVC, usually associated with hydronephrosis, results from anomalous development of the IVC and requires surgery in symptomatic cases. Patients present in their third to fourth decade of life with right flank pain \& discomfort, urinary tract infections, haematuria, or fever. MDCT \& MRI having the capability of simultaneously outlining the ureter and IVC is probably the diagnostic modalities of choice, avoiding the possible complications and expense of an invasive procedure. The open uretero-ureterostomy remained the gold standard surgical approach to treat the circumcaval ureter for many years however, minimally invasive laparoscopic procedures have almost replaced open surgery.

\section{References}

1. Resnick MI, Kurush ED (1992) Extrinsic obstruction of the ureter, In: Walsh P, et al. (Eds.), Campbells Urology, $6^{\text {th }}$ (edn), WB Saunders, Philadelphia, US, pp. 533-569.

2. Uthappa MC, Anthony D, Allen C (2002) Case report: Retrocaval ureter: MR appearances. Br J Radiol 75(890): 177-179.

3. Lautin EM, Haramati N, Frager D, Friedman AC, Gold K, et al. (1988) CT diagnosis of circumcaval ureter. AJR Am J Roentgenol 150(3): 591-594.

4. Rubinstein I, Cavalcanti AG, Canalini AF, Freitas MA, Accioly PM (1999) Left retrocaval ureter associated with inferior vena caval duplication. J Urol 162(4): 1373-1374.

5. Heslin JE, Mamonas C (1951) Retrocaval ureter: Report of four cases and review of literature. J Urol 65(2): 212-222.

6. Bateson EM, Atkinson D (1969) Circumcaval ureter: a new classification. Clin Radiol 20(2): 173-177.

7. Hochstetter F (1893) Beitrage zur entwicklungsgeschichte des venensystems der amnioten III. Sauger Morph Jahrb 20: 542.

8. Cao Avellaneda E, Server Pastor G, Lopez Lopez AI, Maluff Torres A, López Cubillana P, et al. (2005) Non obstructive retrocaval ureter. Actas Urol Esp 29(1): 107-109.

9. Chuang VP, Mena CE, and Hoskins PA (1974) Congenital anomalies of the inferior vena cava. Review of embryogenesis and presentation of a simplified classification. Br J Radiol 47(556): 206-213.

10. Brooks RJ (1962) Left retrocaval ureter associated with situs inversus. J Urol 88: 484-487.

11. Kokubo T, Okado Y, Yashiro N, Itai Y, Lio M (1990) CT diagnosis of retrocaval ureter associated

with double inferior vena cava: report of a case. Radiat Med 8(3): 96-98.

12. Ishitoya S, Arai Yes, Okubo K, Suzuki Y, Waki K (1997) Left retrocaval ureter associated with the Goldenhar Syndrome (Brachial arch syndrome). J Urol 158(2): 572-573.

13. Novelline RA, Rhea JT, Rao PM, Stuk JL (1999) Helical CT in emergency radiology. Radiology 213(2): 321-339.

14. Bass FE, Redwine MD, Kramer LA, Huynh PT, Harris JH (2000) Spectrum of congenital anomalies of the inferior vena cava: cross-sectional imaging findings. Radio Graphics 20(3): 639-652.

15. Bhandarkar DS, Lalmalani JG, Shivde S (2003) Laparoscopic ureterolysis and reconstruction of a retrocaval ureter. Surg Endosc 17(11): 1851-1852.

16. Tobias-Machado M, Lasmar MT, Wroclawski ER (2005) Retroperitoneoscopic surgery with extracorpo-real uretero-ureteral anastomosis for treating retro-caval ureter. Int Braz J Urol 31(2): 147150 . 
Your next submission with Juniper Publishers will reach you the below assets

- Quality Editorial service

- Swift Peer Review

- Reprints availability

- E-prints Service

- Manuscript Podcast for convenient understanding

- Global attainment for your research

- Manuscript accessibility in different formats

( Pdf, E-pub, Full Text, Audio)

- Unceasing customer service

Track the below URL for one-step submission https://juniperpublishers.com/online-submission.php 